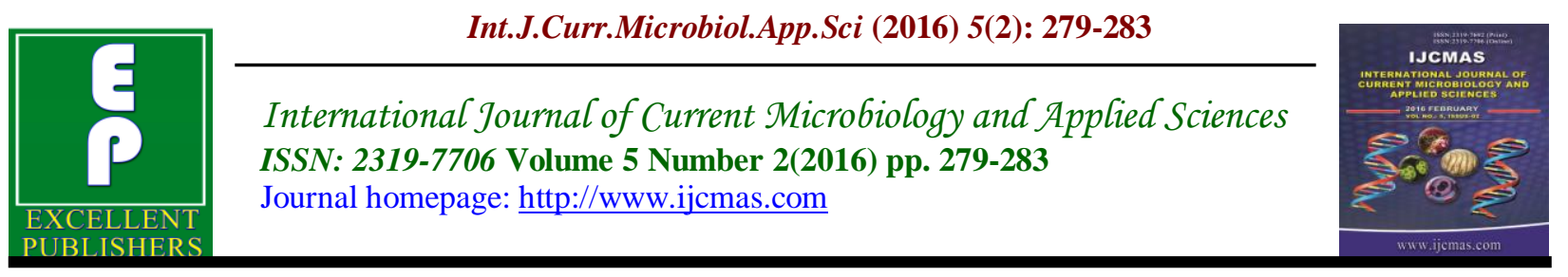

Original Research Article

doi: http://dx.doi.org/10.20546/ijcmas.2016.502.032

\title{
Opportunistic Intestinal Parasites in HIV infected individuals and its Correlation with the CD4 Counts
}

\author{
Y. A. Surekha, H. S. Shilpa*, Mariraj Jeer and S. Krishna \\ Department of Microbiology, Vijayanagar Institute of Medical Science, \\ Ballari -583104 Karnataka, India \\ *Corresponding author
}

\begin{abstract}
A B S T R A C T
Keywords

Opportunistic

intestinal

infection,

HIV,

Diarrhoea,

CD4 Counts

Article Info

Accepted:

15 January 2016

Available Online:

10, February 2016

The association between intestinal parasitic infections and human immunodeficiency virus (HIV) infection is well documented. These infections are often correlated with the CD4+T cell counts of the individuals To study the opportunistic intestinal infections in HIV sero positive patients attending both inpatients and out- patients department VIMS hospital, Ballari Study included Samples of adult and paediatric in- patients of both sexes with confirmed HIV infection with and without diarrhoea attending VIMS hospital, Ballari . CD4 counts were estimated using FACS count system . Study period was from January $1^{\text {st }} 2014$ to December $30^{\text {th }} 2014$.Direct microscopy by saline wet mount and Iodine wet mount was done for identifying parasitic ova, cysts and trophozoites. Modified Z-N staining was done to identify acid fast structures. Out of 120 samples collected 54 $(45 \%)$ samples were found positive for parasitological examination .Among 54 positive samples 28 samples $(23.33 \%)$ showed Cryptosporidium parvum followed by 14 samples (11.66\%) Entameoba histolityca \& Isospora belli 5(4.16\%), Taenia $5(4.16 \%)$ \& Giardia lamblia $2(1.66 \%)$ sample. The prevalence of intestinal parasitic infections remains significant in HIV-infected patients with low CD4 counts $<200$ cells/micro litre.
\end{abstract}

\section{Introduction}

HIV infection/AIDS is a global pandemic, with cases reported from virtually every country. At the end of 2009, an estimated 33.3 million individuals were living with HIV infection according to the Joint United Nations Programme on HIV/AIDS (UNAIDS). It includes 31.3 million adults and 2.1 million children. ${ }^{1}$ One of the major health problem among HIV sero positive patients is superimposed infection due to defect in immunity. ${ }^{2}$
The progressive decline and ultimate destruction of immune system functions, which are characteristic for AIDS, usually result in morbidity and ultimately death due to opportunistic bacterial, viral, fungi and parasitic infections. Gastrointestinal infections are very common in patients with HIV infection or AIDS. Diarrhoea is a common clinical presentation of these infections. Reports indicate that diarrhoea occurs in 30-60\% of AIDS patients in 
developed countries and in about $90 \%$ of AIDS patients in developing countries ${ }^{3}$

The association between intestinal parasites and human immunodeficiency virus (HIV) infection is well documented. The intracellular intestinal protozoans are Cryptosporidium parvum, Cyclospora cayetanensis, Isospora belli and the Microsporidia are opportunistic in patients with acquired immunodeficiency syndrome (AIDS) and are often the major cause of uncontrollable, debilitating diarrhoea ${ }^{4}$

The incidence and prevalence of infection with a particular enteric parasite in HIV/AIDS patients is likely to depend upon the endemicity of that particular parasite in the community. ${ }^{5}$ Early diagnosis, antiretroviral therapy, chemoprophylaxis and treatment of opportunistic infections are important for the control of HIV replication and disease progression.

Hence the current study was conducted to determine the prevalence of enteric opportunistic parasitic infections among HIV-sero positive patients with and without diarrhoea and their association with immune status i e CD4 counts in HIV infected patients in Ballari, Karnataka

\section{Materials and Methods}

Study comprised of all HIV sero positive patients, with diarrhoea and without diarrhoea during a period of one year i e, from January $1^{\text {st }} 2014$ to December 2014. Total 120 subjects were included in the study. The stool samples from these patients were collected in a wide mouthed container with a tight fitting leak proof lid and were examined for various enteric parasites. Their CD4+ $\mathrm{T}$ cell counts were determined and clinical profile was studied by reviewing their case papers and filling a pre-designed
Performa. All HIV sero positive patients of all ages and both sexes who were tested for CD4+ $\mathrm{T}$ cell counts at Integrated Counselling and Testing Centre (ICTC) of Department of Microbiology were included in the study and all HIV sero negative patients detected at ICTC were excluded from the study. The protocol was reviewed and approved by the Institutional Ethics Committee.

Stool samples were examined in wet saline mounts and in iodine preparation for detection of protozoan oocysts, cysts, helminthic ova and larvae. Permanent stained smears were performed with Modified Ziehl-Neelsen staining (Cold Method) for detection of oocysts of $\underset{6}{C}$ Cryptosporidium, Isospora and Cyclospora

The CD4+ T-lymphocytes cell counts from the EDTA blood specimens of the HIV seropositive patients were determined by FACS Count System (Becton Dickinson) . FACS stands for fluroscence activated cell sorting (FACS) . A laser beam is directed at cells suspended in a liquid flow CD4 cells recognised by their flurochrome labelled monoclonal antibody. A built-in computer processes and analyzes the data from the photodetectors \& sensors and computes a CD4 cell count.

This system is an automated instrument designed specifically for enumerating the absolute cell counts of CD4+ and CD3 Tlymphocytes in unlysed whole blood. Guidelines for performance of the test, biosafety practices, trouble shooting and maintenance of equipment were strictly followed as recommended by the manufacturer for maintaining accuracy, reproducibility and comparability of the estimates. $^{7}$ 


\section{Results and Discussion}

A total of $120 \mathrm{HIV}$ sero positive patients with low CD4 counts were included in this study, of which $70(58.33 \%)$ were males, 50 $(41.66 \%)$ were females . Majority of patients, $57(47.5 \%)$ were in the age group of $31-40$ years and $30(25 \%)$ were in the age group of 21-30 years.

Out of 120 , table 1 shows a total of 92 patients $(76.66 \%)$ had diarrhoea and 28 patients $(23.33 \%)$ did not have diarrhoea Out of 92 paitients $70(76.08 \%)$ patient CD4 count was $<200$ cells/microlitre $18(19.56 \%)$ were with CD 4 count ranging between 200500 cells/microlitre followed by $8(4.32 \%)$ patients whose CD 4 count was $>500$ cells/ microlitre Majority of patients 50/57 (87.19\%), were in age group of 31-40 years and maximum number of patients also had diarrhoea. No statistical association was found between age of the patients and diarrhoea.

Out of 120 samples collected 54 (45\%) samples were found positive for parasitological examination . Among 54 positive samples 28 samples (23.33\%) showed Cryptosporidium parvum followed by 14 samples (11.66\%) Entameoba histolityca \& 5 Isospora belli (4.16\%), Taenia $5(4.16 \%)$ \& 2Giardia lamblia $(1.66 \%)$ sample.

Table 2 shows out of 120 patients 88 patients were CD4 count $<200$ cells/micro litre . Among 88 samples 21(0.75) showed Cryptosporidium parvum followed by 11(0.75) Entameoba histolityca and 5 (0.1) Isospora belli, Taenia3(0.6), Giardia lamblia 1(0.5). 24 patients CD 4 count were ranging between 200-500 cells /micro litre showed 5(0.17) Cryptosporidium parvum and Entameoba histolityca1(0.71), Taenia1(0.2), Giardia lamblia1(0.5).8 patients CD4 count were $>500$ cells/micro litre showed Cryptosporidium parvum2(0.07), Entameoba histolityca 2(0.14), Taenia $1(0.2)$

Persistent diarrhoea has been considered as an AIDS defining condition ${ }^{7}$. Many studies have shown that the CD4+ $\mathrm{T}$ cell count is the best indicator of the immediate state of immunologic competence of the patient with HIV infection. It is one of the most widely used surrogate markers for monitoring disease progression and initiating therapy in HIV sero positive persons. In untreated HIV infection, the CD4+ T cell count declines by approximately $4 \%$ per year ${ }^{8}$.

In the present study the enteric parasites were detected in $45 \%$ from the samples with diarrhoea and without diarrhoea. There was significant difference in the infection of opportunistic parasites among HIV- sero positive cases with diarrhoea $40.83 \%$ (49/54) and without diarrhoea 4.16\% (5/54) with CD4 count <200cells /micro litre. .

Table.1 CD4 T Cell Count Vs Diarrhoea Cases

\begin{tabular}{|c|c|c|c|}
\hline CD4 T cell count & Diarrhoea present & Diarrhoea absent & Total \\
\hline$<200$ & $70(76.08 \%)$ & $18(64.28 \%)$ & 88 \\
\hline $200-500$ & $18(19.56 \%)$ & $06(21.42 \%)$ & 24 \\
\hline$>500$ & $04(4.32 \%)$ & $04(14.28 \%)$ & 08 \\
\hline Total & $92(76.66 \%)$ & $28(23.33 \%)$ & 120 \\
\hline
\end{tabular}


Table.2 Parasites Detected in HIV Sero Positive Patients in Correlation CD4 +T Cell Count

\begin{tabular}{|c|c|c|c|c|}
\hline Parasites detected & $<200$ cells/micro litre & 200-500cells/micro litre & $\begin{array}{l}>500 \text { cells/micro } \\
\text { litre }\end{array}$ & Total \\
\hline Cryptosporidium parvum & $21(0.75)$ & $5(0.17)$ & $2(0.07)$ & 28 \\
\hline Entameoba histolityca & $11(0.75)$ & $1(0.71)$ & $2(0.14)$ & 14 \\
\hline Isospora belli & $5(0.1)$ & $0(0.0)$ & $0(0.0)$ & 5 \\
\hline Taenia & $3(0.6)$ & $1(0.2)$ & $1(0.2)$ & 5 \\
\hline Giardia lamblia & $1(0.5)$ & $1(0.5)$ & $0(0.0)$ & 2 \\
\hline $\begin{array}{c}\text { No parasites in stool } \\
\text { examination }\end{array}$ & $47(0.69)$ & $16(0.23)$ & $3(0.04)$ & 68 \\
\hline Total & 88 & 24 & 8 & 120 \\
\hline
\end{tabular}

The prevalence of Cryptosporidium infection at $12 \%$ was found be highest in a study conducted by V. Kulkarni et $\mathrm{al}^{9}$. In their study they found intestinal parasitic infections in $35 \%$ patients. Other pathogens included were Isospora belli 8\%, Entamoeba histolytica/Entamoeba dispar $7 \%$, Microsporidia $1 \%$ and Cyclospora $0.7 \%$. C.parvum were the most commonly observed pathogen $(54 \%)$ with CD4 count $<200 / \mathrm{mm}^{3}$

Study done by $\mathrm{S}$ Sathish Kumar, $\mathrm{S}$ Ananthan, $\mathrm{P}$ Lakshmi $^{10}$ showed Isospora belli $(18 \%)$ associated with diarrhoea. Detection rate of Microsporidia and Cyclospora was found to be very low.

In the study done by Shimelis Assefa, Berhanu Erko, Girmay Medhin, Zelalem Aseefa Techalew Shimelis ${ }^{11}$ in their study found parasitic infection among HIV positive were $55 \%$.Most common helminths A.lumbricoides $12.2 \%, \quad$ T.trichiura, $3.7 \%$, hookwormspecies,3.3\%, E.vermicularis $0.9 \%$, S.stercoralis $12.6 \%$, Taenia species $1.4 \%$, H.nana 1.9\%, S.mansoni $1.9 \%$. and common protozoa, E.histolytica/dispar 24\%, G.lamblia 11.2\%, I.belli $12.2 \%$, Cyptosporidium species $20.1 \%$, E.coli1.9\%, T.hominis $0.9 \%$ were common with CD4 count $<200 \mathrm{~mm}^{3}$.

In one more study conducted by Venkatesh Naik R1, H Ravichandraprakash ${ }^{12}$ et al Out of the 359 HIV positive patients with diarrhoea, enteric parasites were isolated from $195(54.31 \%)$ of HIV positive patients with diarrhoea compared to $12(12 \%)$ of HIV positive patients without diarrhoea. Cryptosporidium parasite $(15.87 \%)$ was the predominant parasite isolated in HIV positive patients with diarrhoea followed by Isospora belli (10.02\%) and Cyclospora sp $(5.84 \%)$. The maximum parasitic isolation was in the patients with CD4+ T cell counts $<200$ cells $/ \mu 1$.

In conclusion, the prevalence of intestinal parasitic infections remains significant in HIV-infected patients with CD4 counts < 200 cells /micro litre . The study indicated that enteric parasitic infection caused diarrhoea $(45 \%)$ of the HIV-sero positive patients. The current finding also highlights the importance of early detection of opportunistic parasitic infections among HIV-sero positive patients with low CD4 counts. This may help to improve the management and quality of life of HIVinfected individuals. Enteric parasites in order to avoid morbidity and mortality due to opportunistic pathogens causing diarrhoea in HIV patients.

\section{References}

1. Longo, Fauc, Kasper, Hauser, Jameson, Loscalzo- Harrison's Principles Of 
Internal Medicine, $18^{\text {th }}$ Edition. Vol 1. PP 1516- 1587

2. Lynne Shore Garcia-Diagnostic Medical Parasitology, $5^{\text {th }}$ Edition

3. Sherchan JB,1 Ohara H,2 Sakurada S,2 Basnet A,3 Tandukar S, Sherchand JB, 3 Bam D S4 Enteric Opportunistic Parasitic Infections Among HIVSeropositive Patients in Kathmandu, Nepal J 2012;38(2):14-17.

4. Amol Zope*,Anand Pai, Anuradha De, and Sujatha M Baveja Opportunistic Intestinal Parasites in HIV Infected Individuals and Its Correlation with the CD4 Counts Department of Microbiology,Lokamanya Tilak Municipal Medical College, Mumbai40022, Maharashtra, India. 2014;3(3):55-60

5. Janoff EN, Smith PD. Prospectives on gastrointestinal infections in AIDS. Gastroenterol Clin North Am 1988;17:451-463

6. Textbook of Medical Parasitology Protozoology \& Helminthology Text and colour atlas fourth edition Page no :335

7. District Laboratory Practice in Tropical Countries Second Edition Update Page no: 264

8. Betts MR, Ambrozak DR, Douek DC, Bonhoefer S. Analysis of total Human Immunodeficiency Virus (HIV) specific CD4+ and CD8+ T-cell responses: Relationship to viral load in untreated HIV infection. J Virol. 2001;75:11983-91.

9. S.V Kulkari, R.Karion,S. S. Sane. P.S. Padmavar-Opportunistic parasitic intestinal infections in HIV/AIDS Patient presenting with diarrhoea by the level of immunesuppression -Natonal AIDS Research Institute,pune.India.Indian journal med Res, july 2009,pp 63-66.

10. S.Satheesh Kumar, Ananthan S, Lakshmi p- Intestinal parasitic infection in HIV infected patients with diarrhoea in Chennai, Indian $j$ medical microbiology 2002, 20,88-91

11. Shimelis Assefa, Berhanu Erko,Girmay Medhin,Zelalem Aseefa Techalew Shimelis- Intestinal parasitic infections in relations to HIV/AIDS status diarrhoea andCD4 cell count.BMC infectious Diseases 2009,9:155.

12. Venkatesh Naik R1, H Ravichandraprakash2, Ukey Pm3, Vijayanath V4, Shreeharsha G5, Vinay Kumar Chand Opportunistic Intestinal Parasitic Infections In Hiv/Aids Patients Presenting With Diarrhea And Their Correlation With Cd4+ T-Lymphocyte Counts International Journal of Pharmacy and Biological Sciences (eISSN: 2230-7605).

\section{How to cite this article:}

Surekha, Y. A., H. S. Shilpa, Mariraj Jeer and Krishna, S. 2016. Opportunistic Intestinal Parasites in HIV infected individuals and its Correlation with the CD4 Counts. Int.J.Curr.Microbiol.App.Sci. 5(2): 279-283. doi: http://dx.doi.org/10.20546/ijcmas.2016.502.032 